Cretaceous-Tertiary extinctions

\section{Physical evidence of impact}

\section{from Richard $A, F$. Grieve}

SINCE the original reports four years ago of abnormal abundances of iridium and other siderophiles at the Cretaceous-Tertiary $(\mathrm{K}-\mathrm{T})$ boundary, there has been intense interest in the possibility that they represent the geochemical signature of a large impact event that is causally related to contemporaneous mass faunal extinctions. Evidence of equivalent anomalies at boundary sites throughout the world shows they are a global phenomenon. In the meantime, there have been detailed searches for physical evidence of largescale impact at the K-T boundary. Such evidence is now forthcoming, which makes it virtually certain that such an impact did take place.

Some of the physical evidence is reported by Jan Smit and Frank Kyte on page 403 of this issue of Nature. They describe sandsized microtektite-like spherules at two boundary sites in Italy. There are three types: sanidine-, glauconite- and magnetite-bearing. Although the chemistry and texture of much of the spherule mass have changed over geological time, the magnetite grains in the spherules are believed to have retained their original characteristics. They are enriched in iridium and have approximately chondritic abundances of other siderophiles. In texture, they resemble rapidly-crystallized high-temperature liquids. Smit and Kyte conclude that they are the result either of shock-melting of mafic, possibly oceanic, crustal material or of atmospheric melting and ablation of a mafic projectile.

Spherules from the K-T boundary have been reported previously at Caravaca, Spain (Nature 292, 47; 1981), at another Italian site and in DSDP hole 465A in the central Pacific (Geology 11, 668; 1983). Similar occurrences in DSDP hole 577A from the North Pacific, reported by Kyte and Smit, indicate that, like the geochemical anomaly, these spherules are not a local phenomenon. The suggestion that the magnetite-bearing spherules originate as melted oceanic crustal material is supported by isotopic data (Earth planet. Sci. Lett. 60, 155; 1982, and 64, 356; 1983) that identify a component of oceanic crustal material, considered to be impact fallout, in the boundary layer.

Although the altered character of the boundary-layer spherules puts the interpretation of their impact origin in some doubt, there is independent physical evidence of impact at the K-T boundary. Bohor et al. (Science 224, 867; 1984) recently recovered quartz grains with microscopic planar deformation features and lowered refractive indices from the boundary layer in Montana, USA. These

\section{Astronomy}

features are part of a suite of features known collectively as shock metamorphic features, which are unequivocal evidence of impact. The orientations of the planar features are indicative of shock pressures of scale $15 \mathrm{GPa}$ ( $150 \mathrm{kbar}$ ). Shocked quartz has now been reported from sites in New Mexico, in Spain and from two sites in both Denmark and Italy. So it seems that the occurrence of shocked quartz, too, is not a local phenomenon.

Details of the K-T event are still open to interpretation, however, and the evidence itself raises some questions. The spherules and the isotopic data suggest an oceanic impact. On the other hand, the shocked quartz could be interpreted in terms of a continental impact. In the Montana section, shocked quartz constitutes only 0.01 per cent of the boundary claystone. On the basis of isotopic data, there is an estimated 15-20 per cent terrestrial fallout material in the marine section at Caravaca, Spain. Assuming 0.01 per cent quartz for the boundary layer, this gives a quartz component of approximately 5 per cent in the terrestrial detritus. Perhaps the data can be reconciled by postulating an impact involving oceanic crust and a small component of overlying continentallyderived sedimentary materials. Alternatively, one could invoke other more ad hoc explanations involving a number of impacts and thus targets.
The question of the target involved in the $\mathrm{K}-\mathrm{T}$ event has a bearing on the mechanism of the impact-induced extinctions. An oceanic impact might induce short-term elevated temperatures through a greenhouse effect from increased water vapour in the atmosphere. On the other hand, a continental impact would conform more closely to the original hypothesis of Alvarez et al. (Science 208, 1095; 1980), which suggests reduced photosynthesis as a result of obscuration by impact ejecta dust.

With the strong evidence of impact at the $\mathrm{K}-\mathrm{T}$ boundary, there is an understandable desire to relate other mass extinction events to large-scale impact. The FrasnianFamennian extinction event, for example, has been suggested as a likely candidate. A number of recent papers have linked the extinction record with periodic extraterrestrial phenomena, including cometary showers (Nature 308, 709; 1984). If correct, this has far-reaching conclusions. These postulated links should be viewed with caution, however, as they are based on models and statistical analyses of small samples. They offer no geochemical or physical evidence of impact affecting the Earth on a global scale. If the K-T event has abundant physical evidence but still lacks a 'smoking gun' in the form of an impact structure of commensurate age and size, it is not clear whether even 'shots have been fired' at these other extinction events. Careful and detailed work must continue in searching for and investigating the evidence for large-scale impact in the biostratigraphical record.

Richard A.F. Grieve is in the Earth Physics Branch, Department of Energy, Mines \& Resources, Ottawa, Canada K1A OY3.

\title{
IRAS circular 13
}

The source name consists of four parts: (1) the letters 'IRAS' to indicate the origin; (2) the right ascension (RA) in hours and minutes, seconds omitted; (3) declination (Dec) in decimal degrees, multiplied by 10 and then truncated (i.e. $+32 \mathrm{deg} 42.3$ arc $\min =>+327$ ); (4) an appendix starting with ' $P$ ' and followed by the number of the circular. This appendix stresses that the data are preliminary. Position is given at Equinox 1950.0. Measurements were made between epochs 1983.1 and 1983.8. am, arc min. "Source is extended at this wavelength; a point source flux is not quoted.

\begin{tabular}{|c|c|c|c|c|c|c|c|}
\hline \multirow{2}{*}{$\begin{array}{l}\text { Source } \\
\text { IRAS }\end{array}$} & \multicolumn{2}{|l|}{ RA } & Dec & \multicolumn{4}{|c|}{ Flux densities (Janskys) } \\
\hline & $\mathrm{h} \mathrm{min}$ & $\mathbf{s}$ & deg am & $12 \mu \mathrm{m}$ & $25 \mu \mathrm{m}$ & $60 \mu \mathrm{m}$ & $100 \mu \mathrm{m}$ \\
\hline $0532+098 \mathrm{P} 10$ & 0532 & 23 & +0953.5 & 1.4 & 7.1 & 2.2 & $<4$ \\
\hline $0536-026 \mathrm{P} 10$ & 0536 & 14 & -0237.6 & 5.0 & 15.1 & $<10$ & $<15$ \\
\hline $0919-453 P 13$ & 0919 & 28 & $-45 \quad 18.1$ & 47 & 38 & 6.0 & $<4$ \\
\hline $0944-478 P 13$ & 0944 & 51 & -4748.0 & 38 & 46 & 11 & $<4$ \\
\hline $0945-472 \mathrm{P} 13$ & 0945 & 02 & $-47 \quad 16.7$ & 41 & 37 & 9.5 & $<3$ \\
\hline $0947-462 \mathrm{P} 13$ & 0947 & 06 & $-46 \quad 17.5$ & 3.2 & 4.4 & 1.5 & $<2$ \\
\hline $0957-313 \mathrm{P} 13$ & 0957 & 52 & $-31 \quad 18.7$ & 0.42 & 0.91 & 9.0 & 21 \\
\hline $1012-286 \mathrm{P} 13$ & 1012 & 24 & $-28 \quad 37.4$ & $<1.3^{*}$ & $<4^{*}$ & 14 & 39 \\
\hline $1013-413 \mathrm{P} 13$ & 1013 & 53 & $-41 \quad 18.4$ & $<0.2$ & $<0.7^{*}$ & 4.2 & 8.4 \\
\hline $1021-284 P 13$ & 1021 & 57 & $-28 \quad 28.5$ & $<0.2$ & 1.0 & 5.4 & 7.1 \\
\hline $1029-396 \mathrm{P} 13$ & 1029 & 24 & -3942.0 & $<0.8^{\star}$ & $<1.8^{\star}$ & 7.7 & 18 \\
\hline $1248+482 \mathrm{P} 13$ & 1248 & 22 & $+48 \quad 12.3$ & $<0.2$ & 0.57 & 5.7 & 9.8 \\
\hline $1252+468 \mathrm{P} 13$ & 1252 & 20 & +4648.1 & $<1^{*}$ & $<1.4^{*}$ & 5.5 & 18 \\
\hline $1303+419 P 13$ & 1303 & 34 & +4159.4 & $<0.5$ & $<0.3$ & 2.0 & 5.5 \\
\hline $1309+469 P 13$ & 1309 & 03 & +4658.0 & $<0.2$ & $<0.3$ & 3.2 & 7.2 \\
\hline $1323+435 \mathrm{P} 13$ & 1323 & 04 & +4331.5 & 0.41 & 0.68 & 7.2 & 16 \\
\hline $1325+479 P 13$ & 1325 & 25 & +4754.7 & $<0.2$ & $<0.2$ & 2.0 & 3.3 \\
\hline $2002+320 P 10$ & 2002 & 38 & +3204.5 & 2.5 & 16 & 52 & 86 \\
\hline
\end{tabular}

